\title{
Compulsive sexual behavior disorder in obsessive-compulsive disorder: Prevalence and associated comorbidity
}

\author{
JOHANNES FUSS ${ }^{1 *}$, PEER BRIKEN $^{1}$, DAN J. STEIN ${ }^{2,3}$ and CHRISTINE LOCHNER ${ }^{2,3}$ \\ ${ }^{1}$ Institute for Sex Research, Sexual Medicine and Forensic Psychiatry, Center of Psychosocial Medicine, \\ University Medical Center Hamburg-Eppendorf, Hamburg, Germany \\ ${ }^{2}$ MRC Unit on Risk and Resilience in Mental Disorders, Department of Psychiatry and Mental Health, University of Cape Town, Cape Town, \\ South Africa \\ ${ }^{3}$ MRC Unit on Risk and Resilience in Mental Disorders, Department of Psychiatry, University of Stellenbosch, Cape Town, South Africa
}

(Received: December 27, 2018; revised manuscript received: March 20, 2019; accepted: April 7, 2019)

\begin{abstract}
Background and aims: Compulsive sexual behavior disorder (CSBD) will be included in ICD-11 as an impulsecontrol disorder. CSBD also shares clinical features with obsessive-compulsive spectrum disorders (OCSDs) and behavioral addictions. There has been relatively little systematic investigation of CSBD in obsessive-compulsive disorder (OCD), the paradigmatic compulsive disorder. We aimed to determine prevalence of CSBD in OCD, and its associated sociodemographic and clinical features, including associated comorbidity, to learn more about the nature of CSBD. Methods: Adult outpatients with current $\operatorname{OCD}(N=539)$ participated in this study. The Structured Clinical Interview for OCSDs was used to diagnose OCSDs (Tourette's syndrome, compulsive shopping, pathological gambling, kleptomania, pyromania, intermittent explosive disorder, self-injurious behavior, and CSBD). Prevalence rates of OCSDs in male versus female patients as well as comorbid disorders in OCD patients with and without CSBD were compared. Results: Lifetime prevalence of CSBD was 5.6\% in patients with current OCD and significantly higher in men than women. OCD patients with and without CSBD were similar in terms of age, age of onset of OCD, present OCD illness severity, as well as educational background. Lifetime prevalence rates of several mood, obsessive-compulsive, and impulse-control disorders were considerably elevated in patients with lifetime CSBD. Discussion and conclusions: A substantive number of OCD patients suffered from CSBD. CSBD in OCD was more likely comorbid with other mood, obsessive-compulsive, and impulse-control disorders, but not with disorders due to substance use or addictive behaviors. This finding supports conceptualization of CSBD as a compulsive-impulsive disorder.
\end{abstract}

Keywords: hypersexuality, hypersexual disorder, behavioral addictions, compulsivity, impulsivity, compulsive sexual behavior disorder

\section{INTRODUCTION}

Numerous terms have been used to describe excessive sexual behaviors, including compulsive sexual behavior, hypersexuality, sexual addiction, sexual impulsivity, and impulsive-compulsive sexual behavior. There is continuing controversy about labeling "out-of-control" sexual behavior as an "addiction," as a compulsive or as an impulsive disorder (Bőthe, Bartók, et al., 2018; Bőthe, Tóth-Király, et al., 2018; Carnes, 1983, 1991; Fuss et al., 2019; Gola \& Potenza, 2018; Grant et al., 2014; Griffiths, 2016; Kraus, Voon, \& Potenza, 2016; Potenza, Gola, Voon, Kor, \& Kraus, 2017; Stein, 2008; Stein, Black, \& Pienaar, 2000). In addition, despite scientific support for inclusion of the condition into diagnostic manuals, there has also been substantial advocacy against this, based on the risk of pathologizing of normal sexual behavior due to religious, moralistic, or sex-negative attitudes (Fuss et al., 2019; Klein, Briken, Schröder, \& Fuss, in press). Indeed, the proposal for the inclusion of hypersexual disorder into the fifth edition of the Diagnostic and Statistical Manual of Mental Disorders (DSM-5; Kafka, 2010) was denied by the American Psychiatric Association (APA) board of trustees (Kafka, 2014). Inclusion of compulsive sexual behavior disorder (CSBD) as an impulse-control disorder in the 11th revision of the International Statistical Classification of Diseases and Related Health Problems (ICD-11) is due for official ratification in 2019 (Kraus et al., 2018).

Partly due to the controversy about the disorder, the lack of officially accepted diagnostic criteria, and the lack of a validated diagnostic instrument, few rigorous epidemiological studies on CSBD have been carried out. In this article,

* Corresponding author: Johannes Fuss; Institute for Sex Research, Sexual Medicine and Forensic Psychiatry, Center of Psychosocial Medicine, University Medical Center Hamburg-Eppendorf, Martinistraße 52, 20246 Hamburg, Germany; Phone: +49 40 7410 54232; Fax: +49 407410 56406; E-mail: jo.fuss@uke.de

This is an open-access article distributed under the terms of the Creative Commons Attribution-NonCommercial 4.0 International License, which permits unrestricted use, distribution, and reproduction in any medium for non-commercial purposes, provided the original author and source are credited, a link to the CC License is provided, and changes - if any - are indicated. 
we refer to CSBD as a condition characterized by a persistent pattern of failure to control intense, repetitive sexual impulses or urges, resulting in repetitive sexual behavior over an extended period that causes marked distress or impairment in personal, family, social, educational, occupational, or other important areas of functioning (Kraus et al., 2018). It has been estimated that $5 \%-6 \%$ of the general population may be affected by the disorder (Carnes, 1991; Coleman, 1992); however, a recent representative study found even higher rates of distress associated with difficulty controlling sexual feelings, urges, and behaviors in the US (Dickenson, Coleman, \& Miner, 2018). Importantly, these prevalence estimates may be an overestimation due to a lack of research using reliable and validated operational criteria (Klein, Rettenberger, \& Briken, 2014).

Patients with CSBD commonly report compulsive behaviors, impulse-control difficulties, and substance use (Derbyshire \& Grant, 2015). Attention to these comorbidities may ultimately be helpful in the conceptualization of out-of-control sexual behavior as compulsivity, impulsivity, or as an addiction. A recent study found that both impulsivity and compulsivity are related to "out-of-control" sexual behaviors, while the relation to impulsivity was stronger (Böthe, Tóth-Király, et al., 2018). Nevertheless, a relationship between "out-of-control" sexual behavior and compulsivity has repeatedly been suggested (Carnes, 1983, 1991; Coleman, 1991; Stein, 2008) because both phenomena are characterized by repetitiveness and a rise in tension before the behavior, followed by a sense of release during execution. Consequently, the term compulsive sexual behavior disorder has been proposed for "out-of-control" sexual behaviors that are accompanied by distress and problems in functioning for ICD-11 (Kraus et al., 2018). However, there has been relatively little systematic investigation of CSBD in obsessive-compulsive disorder (OCD), the paradigmatic compulsive disorder. In this study, we focused on the comorbidity of CSBD and OCD. Although the prevalence of OCD has previously been assessed in clinical and non-clinical samples of people with compulsive sexual behavior with prevalence rates ranging from $2.3 \%$ to 14\% (Black, Kehrberg, Flumerfelt, \& Schlosser, 1997; de Tubino Scanavino et al., 2013; Morgenstern et al., 2011; Raymond, Coleman, \& Miner, 2003), this is the first study to assess the prevalence of CSBD in OCD patients and its associated sociodemographic and clinical features. Such information may be clinically useful and may also assist in the conceptualization of CSBD.

\section{METHODS}

\section{Participants and procedure}

Adult outpatients with current OCD recruited between January 2000 and December 2017 took part in this study. To be eligible, patients had to meet the fourth edition of DSM (DSM-IV; APA, 2000) criteria for a primary diagnosis of OCD on the Structured Clinical Interview for Diagnostic and Statistical Manual of Mental Disorders, Fourth Edition, Axis I Disorders-Patient Version (SCID-I/P; First, Spitzer, Gobbon, \& Williams, 1998). A history of psychosis was an exclusion criterion. A clinical psychologist or other mental health clinician with OCD expertise interviewed patients referred from a wide range of sources (e.g., the OCD Association of South Africa and community-based primary care practitioners).

\section{Measures}

The semi-structured interview included questions on specific demographic and clinical data including current age, ethnicity, and age of onset of OCD. Clinical diagnoses, including mood, anxiety, substance use, selected somatoform, and eating disorders, were based upon data obtained with the SCID-I/P. In addition, the Structured Clinical Interview for Obsessive-Compulsive Spectrum Disorders (OCSDs) (SCID-OCSD; du Toit, van Kradenburg, Niehaus, $\&$ Stein, 2001) was used to diagnose putative OCSDs, which included Tourette's disorder and DSM-IV impulsecontrol disorders [i.e., Tourette's syndrome, compulsive shopping, pathological gambling, kleptomania, pyromania, intermittent explosive disorder (IED), self-injurious behavior, and CSBD]. Current CSBD was diagnosed when participants presently met all of the following criteria lifetime CSBD was diagnosed when participants met all of the following criteria in the past and/or presence:

- Over a period of at least 6 months, a pattern of failure to control recurrent, intense sexually arousing fantasies, sexual urges, or behaviors that do not fall under the definition of paraphilia.

- The fantasies, sexual urges, or behaviors cause clinically significant distress or impairment in social, occupational, or other important areas of functioning.

- The symptoms are not better accounted for by another disorder (e.g., manic episode, delusional disorder: erotomanic subtype).

- The symptoms are not due to the direct physiological effects of a substance (e.g., a drug of abuse or a medication) or a general medical condition.

The Yale-Brown Obsessive-Compulsive Scale(YBOCS) symptom checklist and severity rating scale were used to assess the typology and severity of obsessive-compulsive symptoms (Goodman, Price, Rasmussen, Mazure, Delgado, et al., 1989; Goodman, Price, Rasmussen, Mazure, Fleischmann, et al., 1989).

\section{Statistical analyses}

Univariate analyses were carried out using IBM SPSS Statistics 22.0 (IBM Corp., Armonk, NY, USA). $\chi^{2}$ and Fisher's exact tests, as appropriate, were performed to compare prevalence rates of OCSDs, including CSBD, between male and female patients with OCD and to compare rates of all comorbidities as assessed during the interview (i.e., Tourette's syndrome, hypochondriasis, substance dependence, substance abuse, alcohol dependence, alcohol abuse, major depressive disorder, dysthymic disorder, bipolar disorder, compulsive shopping, pathological gambling, kleptomania, pyromania, IED, panic disorder with agoraphobia, panic disorder without agoraphobia, agoraphobia without history of panic, social phobia, specific phobia, 
post-traumatic stress disorder, anorexia nervosa, bulimia nervosa, and self-injurious behavior) between OCD patients with and without CSBD. Student's $t$-tests were performed to compare age, age of onset of OCD, and YBOCS score between OCD patients with and without CSBD. Statistical significance was set at $p<.05$.

\section{Ethics}

The study procedures were carried out in accordance with the Declaration of Helsinki. The institutional review board of the University of Stellenbosch (Stellenbosch University Health Research Ethics Committee Reference 99/013) approved the study. All subjects were informed about the study and all provided informed consent.

\section{RESULTS}

Adult outpatients with current $\operatorname{OCD}(N=539 ; 260$ men and 279 women), with ages ranging between 18 and 75 years (mean $=34.8, S D=11.8$ years), participated in this study. Lifetime prevalence of CSBD was $5.6 \%(n=30)$ in patients with current OCD. In male patients, the lifetime prevalence was significantly higher compared to female patients $\left[\chi^{2}(1)=10.3, p=.001\right.$; Table 1]. Overall, 3.3\% $(n=18)$ of the sample reported current CSBD. Again, this was significantly higher in male compared to female patients $\left[\chi^{2}(1)=6.5, p=.011\right.$; Table 1].

CSBD was the second most prevalent impulse-control disorder assessed in this cohort of patients with OCD after IED. The prevalence rates of other impulse-control disorders and pathological gambling (which is cross-listed in Impulse
Control Disorders in ICD-11) are also depicted in Table 1. Compared to OCD patients without CSBD, OCD patients with CSBD reported comparable age, age of onset of OCD, current YBOCS score, as well as a comparable educational and ethnicity (Table 2).

The prevalence rates for comorbid disorders in patients with and without lifetime CSBD are depicted in Table 3. Importantly, Tourette's syndrome, hypochondriasis, kleptomania, bipolar disorder, compulsive shopping, IED, and dysthymia had an odds ratio above 3 with a confidence interval above 1 .

\section{DISCUSSION AND CONCLUSIONS}

In this study, we were interested in the prevalence and the associated sociodemographic and clinical features of CSBD in patients with OCD. First, we found that $3.3 \%$ of patients with OCD had current CSBD and 5.6\% had lifetime CSBD, with a significantly higher prevalence in men than in women. Second, we found that other conditions, particularly mood, obsessive-compulsive, and impulse-control disorders, were more common in OCD patients with CSBD than in those without CSBD, but not disorders due to substance use or addictive behaviors.

The early estimations of prevalence rates of CSBD provided by Carnes (1991) and Coleman (1992) suggested that up to $6 \%$ of people from the general population suffer from compulsive sexual behavior. Although it is unclear how these estimates were obtained (Black, 2000), subsequent epidemiological research confirmed that compulsive sexuality, which may include increased masturbation frequency, pornography use, number of sexual partners, and

Table 1. Lifetime prevalence and current prevalence rates of CSBD compared to other impulse-control disorders in patients with lifetime OCD

\begin{tabular}{|c|c|c|c|c|c|c|}
\hline & \multicolumn{3}{|c|}{ Lifetime diagnoses $[n(\%)]$} & \multicolumn{3}{|c|}{ Current diagnoses $[n(\%)]$} \\
\hline & All & Men & Women & All & Men & Women \\
\hline CSBD & $30(5.6)$ & $23(8.8)$ & $7(2.5)$ & $18(3.3)$ & $14(5.4)$ & $4(1.4)$ \\
\hline Pyromania & $4(0.7)$ & $4(1.5)$ & 0 & $1(0.2)$ & $1(0.4)$ & 0 \\
\hline Kleptomania & $22(4.1)$ & $8(3.1)$ & $14(5.0)$ & $10(1.9)$ & $2(0.8)$ & $8(2.9)$ \\
\hline IED & $70(13.0)$ & $37(14.2)$ & $33(11.8)$ & $40(7.4)$ & $20(7.7)$ & $20(7.2)$ \\
\hline Pathological gambling & $5(0.9)$ & $5(1.9)$ & 0 & 0 & 0 & 0 \\
\hline
\end{tabular}

Note. CSBD: compulsive sexual behavior disorder; OCD: obsessive-compulsive disorder; IED: intermittent explosive disorder.

Table 2. Demographics and clinical characteristics of OCD patients with and without CSBD

\begin{tabular}{lccr}
\hline & $\begin{array}{c}\text { Patients with CSBD } \\
{[n=30(5.6 \%)]}\end{array}$ & $\begin{array}{c}\text { Patients without CSBD } \\
{[n=509(94.4 \%)]}\end{array}$ & $\chi^{2} / t$ \\
\hline Age (mean $\pm S D$; years) & $33.9 \pm 9.8$ & $34.8 \pm 11.9$ & 0.4 \\
Onset age of OCD (mean $\pm S D$; years) & $15.5 \pm 7.6$ & $17.5 \pm 9.9$ & .7 \\
YBOCS score (mean $\pm S D)$ & $21.4 \pm 8.0$ & $20.7 \pm 7.3$ & -0.4 \\
Highest level of education $[n(\%)]$ & & & .3 \\
Only school education & $15(50 \%)$ & $212(42 \%)$ & 0.8 \\
Post-school education & $15(50 \%)$ & $297(58 \%)$ & .4 \\
\hline
\end{tabular}

Note. SD: standard deviation; CSBD: compulsive sexual behavior disorder; OCD: obsessive-compulsive disorder; YBOCS: Yale-Brown Obsessive-Compulsive Scale. 
Table 3. Lifetime prevalence rates of comorbid disorders in OCD patients with and without CSBD

\begin{tabular}{|c|c|c|c|c|c|}
\hline & $\begin{array}{c}\text { Patients with CSBD } \\
{[n(\%)]}\end{array}$ & $\begin{array}{c}\text { Patients without CSBD } \\
{[n(\%)]}\end{array}$ & $\chi^{2}(1)^{\mathrm{a}}$ & $p$ value & Odds ratio $[\mathrm{CI}]$ \\
\hline Tourette's syndrome & $4(13.3)$ & $7(1.4)$ & & .002 & $11.0[3.0-40.1]$ \\
\hline Hypochondriasis & $5(16.7)$ & $11(2.2)$ & 20.7 & $<.001$ & $9.1[2.9-28.1]$ \\
\hline Kleptomania & $5(16.7)$ & $17(3.3)$ & 12.9 & $<.001$ & $5.8[2.0-17.0]$ \\
\hline Bipolar disorder & $4(13.3)$ & $15(2.9)$ & & .017 & $5.1[1.6-16.3]$ \\
\hline Pathological gambling & $1(3.3)$ & $4(0.8)$ & & .250 & $4.4[0.5-40.2]$ \\
\hline Compulsive shopping & $6(20.0)$ & $28(5.5)$ & 10.1 & .002 & $4.3[1.6-11.4]$ \\
\hline IED & $10(33.3)$ & $60(11.8)$ & 11.6 & .001 & $3.77[1.7-8.4]$ \\
\hline Dysthymia & $10(33.3)$ & $72(14.1)$ & 8.1 & .004 & $3.0[1.4-6.7]$ \\
\hline Alcohol abuse & $5(16.7)$ & $33(6.5)$ & 4.5 & .034 & $2.9[1.0-8.0]$ \\
\hline Panic disorder without agoraphobia & $3(10.0)$ & $19(3.7)$ & & .120 & $2.9[0.8-10.3]$ \\
\hline Alcohol dependence & $2(6.6)$ & $14(2.8)$ & & .220 & $2.5[0.5-11.7]$ \\
\hline Self-injurious behavior & $8(26.7)$ & $66(13.0)$ & 4.5 & .034 & $2.4[1.0-5.7]$ \\
\hline Panic disorder with agoraphobia & $5(16.7)$ & $39(7.7)$ & 3.1 & .080 & $2.4[(0.9-6.6]$ \\
\hline Substance abuse & $1(3.3)$ & $3(0.6)$ & & .210 & $2.4[0.5-10.8]$ \\
\hline Post-traumatic stress disorder & $3(10.0)$ & $23(4.5)$ & & .170 & $2.3[0.7-8.3]$ \\
\hline Bulimia nervosa & $3(10.0)$ & $25(4.9)$ & & .200 & $2.2[0.6-7.6]$ \\
\hline Substance dependence & $1(3.3)$ & $11(2.2)$ & & .500 & $1.6[0.2-12.5]$ \\
\hline Social phobia & $4(13.3)$ & $52(10.2)$ & & .540 & $1.4[0.5-4.0]$ \\
\hline Specific phobia & $5(16.7)$ & $70(13.8)$ & & .650 & $1.3[0.5-3.4]$ \\
\hline Major depressive disorder & $21(70.0)$ & $320(62.9)$ & 0.6 & .430 & $1.2[0.7-2.2]$ \\
\hline Anorexia nervosa & $1(3.3)$ & $27(5.3)$ & & 1.000 & $0.6[0.8-4.7]$ \\
\hline Pyromania & 0 & $4(0.8)$ & & 1.000 & - \\
\hline Agoraphobia without panic disorder & 0 & $5(1.0)$ & & 1.000 & - \\
\hline
\end{tabular}

Note. CSBD: compulsive sexual behavior disorder; IED: intermittent explosive disorder; OCD: obsessive-compulsive disorder; CI: confidence interval.

${ }^{\text {a } M i s s i n g}$ when Fisher's exact test was used to compare prevalence rates.

extramarital affairs, is common in the general population (Dickenson et al., 2018). Our findings on prevalence rates of CSBD in OCD seem roughly comparable to those in the general population (Langstrom \& Hanson, 2006; Odlaug et al., 2013; Skegg, Nada-Raja, Dickson, \& Paul, 2010). However, any conclusions about the prevalence of CSBD must be drawn with caution because prevalence rates may be affected by sociocultural factors and so may vary across populations. For example, among male military veterans, the rate of current CSBD seems to be much higher (16.7\%) compared to psychiatric patients $(4.4 \%)$ and university students $(3 \%)$ in the United States using the same interview for CSBD (Grant, Levine, Kim, \& Potenza, 2005; Odlaug et al., 2013; Smith et al., 2014). In addition, a range of different measures and operationalizations of the construct have been used to assess CSBD, thereby limiting the comparability of results. For example, Jaisoorya et al. (2003) used a self-designed measure to detect impulsecontrol disorders based on DSM-IV criteria to compare comorbidity (including sexual compulsions) in patients with OCD $(n=231)$ and control subjects $(n=200)$ in Indian population. They found that only one subject reported a lifetime prevalence of sexual compulsions (which may or may not be comparable to CSBD).

We also found that several comorbidities were more likely in OCD patients with CSBD than in those without CSBD. Four disorders with impulse-control difficulties, namely IED, Tourette's syndrome, kleptomania, and compulsive shopping, were more prevalent in OCD patients with CSBD compared to those without CSBD. The lifetime prevalence of these disorders was also higher than in other reports studying their prevalence in CSBD patients (Black et al., 1997; Raymond et al., 2003), indicating a more pronounced impairment in impulse control in people with both disorders, that is CSBD and OCD. Since ample evidence supports a genetic relationship between some forms of OCD and Tourette's syndrome (Pauls, Leckman, Towbin, Zahner, \& Cohen, 1986; Pauls, Towbin, Leckman, Zahner, \& Cohen, 1986; Swain, Scahill, Lombroso, King, \& Leckman, 2007), our data may also indicate that the same genetic or neurobiological (Stein, Hugo, Oosthuizen, Hawkridge, \& van Heerden, 2000) factors may also predispose individuals to CSBD. We also found a high lifetime prevalence of mood disorders, particularly dysthymia and bipolar disorder in OCD patients with CSBD exceeding earlier reports about comorbidities in CSBD (Raymond et al., 2003). It is pertinent to note that some people use compulsive sexual behavior to cope with stress and negative feelings (Folkman, Chesney, Pollack, \& Phillips, 1992). Thus, CSBD might not only be used for emotion regulation by some patients but may also be a cause of impaired mood due to distress associated with CSBD. Kafka (2010) noted earlier that some hypomanic episodes seem to last significantly shorter than 4 days (Benazzi, 2001; Judd \& Akiskal, 2003), so that subthreshold cases may be falsely classified with CSBD when the displayed sexual behavior is in fact a symptom of bipolar disorder. Our data are consistent with a view that clinicians should be cautious in diagnosing CSBD in patients with bipolar disorder. We also found that the prevalence of another obsessive-compulsive-related 
disorder, hypochondriasis (Coleman, 1991; Jenike, 1989), was significantly elevated in OCD patients with CSBD. Patients with hypochondriasis typically present with preoccupations with bodily health (Salkovskis \& Warwick, 1986). Those with frequent intercourse or masturbation who suffer from hypochondriasis may be particularly at risk of perceiving their sexual behavior as unhealthy. They may be preoccupied with the question whether their sexual desire and behavior is "out-of-control" or within normal boundaries.

\section{Limitations}

Several limitations of this study deserve emphasis. First, this study only included OCD patients without a control group of CSBD patients with no OCD. Findings on CSBD in OCD may not generalize to other diagnostic cohorts, warranting further investigation. Furthermore, these participants did not seek treatment for CSBD and as such may not be the typical population presenting to the clinic with CSBD. In addition, because of the relatively low number of individuals fulfilling CSBD criteria, we did not separate the cohort by gender in further analysis, although the psychopathology of CSBD may differ in men versus women. We also did not correct for multiple comparisons due to the low number of individuals fulfilling CSBD criteria and the exploratory nature of this study.

CSBD was diagnosed using the SCID-OCSD. This instrument assesses the core diagnostic guidelines of CSBD in ICD-11 focusing on distress and impairment (see "Methods" section); however, in the Clinical Descriptions and Diagnostic Guidelines version of ICD-11, concerns about overpathologizing are also addressed to help clinicians (e.g., in the boundaries to normality section). Our instrument was lacking such a boundary section.

\section{Conclusion and future directions}

In conclusion, our data indicate that prevalence rates of CSBD in OCD are comparable to those in the general population and in other diagnostic cohorts. Moreover, we found that CSBD in OCD was more likely comorbid with other impulsive, compulsive, and mood disorders, but not with behavioral- or substance-related addictions. This finding supports the conceptualization of CSBD as a compulsive-impulsive disorder. Going forward, standardized measures with sound psychometric properties are needed to assess presence and severity of CSBD. Future research should continue to consolidate the conceptualization of this disorder and to gather additional empirical data, in order to ultimately improve clinical care.

Funding sources: This research was supported by grants to CL and DJS by the South African Medical Research Council and a grant to JF by the University of Hamburg for a research visit to University of Cape Town, South Africa.

Authors' contribution: CL and DJS supervised study design, obtained funding, and supervised manuscript preparation.
JF conducted statistical analyses. JF and PB wrote the first draft of the manuscript. All authors substantially contributed to the conceptual design of the study and the final version of the manuscript. They had full access to all data in the study and take responsibility for the integrity of the data and the accuracy of the data analysis.

Conflict of interest: The authors report no financial or other relationship relevant to the subject of this article.

\section{REFERENCES}

American Psychiatric Association [APA]. (2000). Diagnostic and statistical manual of mental disorders (4th ed., text rev.). Washington, DC: American Psychiatric Association.

Benazzi, F. (2001). Is 4 days the minimum duration of hypomania in bipolar II disorder? European Archives of Psychiatry and Clinical Neuroscience, 251(1), 32-34. doi:10.1007/s004060 170065

Black, D. W. (2000). The epidemiology and phenomenology of compulsive sexual behavior. CNS Spectrums, 5(1), 26-72. doi:10.1017/S1092852900012645

Black, D. W., Kehrberg, L. L., Flumerfelt, D. L., \& Schlosser, S. S. (1997). Characteristics of 36 subjects reporting compulsive sexual behavior. The American Journal of Psychiatry, 154(2), 243-249. doi:10.1176/ajp.154.2.243

Böthe, B., Bartók, R., Tóth-Király, I., Reid, R. C., Griffiths, M. D., Demetrovics, Z., \& Orosz, G. (2018). Hypersexuality, gender, and sexual orientation: A large-scale psychometric survey study. Archives of Sexual Behavior, 47(8), 2265-2276. doi:10.1007/ s10508-018-1201-z

Bőthe, B., Tóth-Király, I., Potenza, M. N., Griffiths, M. D., Orosz, G., \& Demetrovics, Z. (2018). Revisiting the role of impulsivity and compulsivity in problematic sexual behaviors. The Journal of Sex Research, 56(2), 166-179. doi:10.1080/00224499.2018.1480744

Carnes, P. (1983). Out of the shadows: Understanding sexual addiction. Minneapolis, MI: CompCare Publisher.

Carnes, P. (1991). Don't call it love: Recovering from sexual addiction. New York, NY: Bantam.

Coleman, E. (1991). Compulsive sexual behavior. Journal of Psychology \& Human Sexuality, 4(2), 37-52. doi:10.1300/J056v0 4n02_04

Coleman, E. (1992). Is your patient suffering from compulsive sexual behavior? Psychiatric Annals, 22(6), 320-325. doi:10.3928/ 0048-5713-19920601-09

de Tubino Scanavino, M., Ventuneac, A., Abdo, C. H. N., Tavares, H., do Amaral, M. L. S. A., Messina, B., dos Reis, S. C., Martins, J. P., \& Parsons, J. T. (2013). Compulsive sexual behavior and psychopathology among treatment-seeking men in São Paulo, Brazil. Psychiatry Research, 209(3), 518-524. doi:10.1016/j.psychres.2013.01.021

Derbyshire, K. L., \& Grant, J. E. (2015). Compulsive sexual behavior: A review of the literature. Journal of Behavioral Addictions, 4(2), 37-43. doi:10.1556/2006.4.2015.003

Dickenson, J. A. G. N., Coleman, E., \& Miner, M. H. (2018). Prevalence of distress associated with difficulty controlling sexual urges, feelings, and behaviors in the United States. JAMA Network Open, 1(7), e184468. doi:10.1001/jamanetworkopen. 2018.4468 
du Toit, P. L., van Kradenburg, J., Niehaus, D., \& Stein, D. J. (2001). Comparison of obsessive-compulsive disorder patients with and without comorbid putative obsessive-compulsive spectrum disorders using a structured clinical interview. Comprehensive Psychiatry, 42(4), 291-300. doi:10.1053/comp.2001.24586

First, M. B., Spitzer, R. L., Gobbon, M., \& Williams, J. B. W. (1998). Structured clinical interview for DSM-IV Axis I disorders-Patient edition (SCID-I/P, Version 2.0, $8 / 98$ revision). New York, NY: New York State Psychiatric Institute, Biometrics Research Department.

Folkman, S., Chesney, M. A., Pollack, L., \& Phillips, C. (1992). Stress, coping, and high-risk sexual behavior. Health Psychology, 11(4), 218-222. doi:10.1037/0278-6133.11.4.218

Fuss, J., Lemay, K., Stein, D. J., Briken, P., Jakob, R., Reed, G. M., \& Kogan, C. S. (2019). Public stakeholders' comments on ICD-11 chapters related to mental and sexual health. World Psychiatry, 18, 2. doi:10.1002/wps.20635

Gola, M., \& Potenza, M. N. (2018). Promoting educational, classification, treatment, and policy initiatives: Commentary on: Compulsive sexual behaviour disorder in the ICD-11 (Kraus et al., 2018). Journal of Behavioral Addictions, 7(2), 208-210. doi:10.1556/2006.7.2018.51

Goodman, W. K., Price, L. H., Rasmussen, S. A., Mazure, C., Delgado, P., Heninger, G. R., \& Charney, D. S. (1989). The Yale-Brown Obsessive Compulsive Scale. II. Validity. Archives of General Psychiatry, 46(11), 1012-1016. doi:10.1001/ archpsyc.1989.01810110054008

Goodman, W. K., Price, L. H., Rasmussen, S. A., Mazure, C., Fleischmann, R. L., Hill, C. L., Heninger, G. R., \& Charney, D. S. (1989). The Yale-Brown Obsessive Compulsive Scale. I. Development, use, and reliability. Archives of General Psychiatry, 46(11), 1006-1011. doi:10.1001/archpsyc.1989. 01810110048007

Grant, J. E., Atmaca, M., Fineberg, N. A., Fontenelle, L. F., Matsunaga, H., Reddy, Y. C. J., Simpson, H. B., Thomsen, P. H., van den Heuvel, O. A., Veale, D., Woods, D. W., \& Stein, D. J. (2014). Impulse control disorders and "behavioural addictions" in the ICD-11. World Psychiatry, 13(2), 125-127. doi:10.1002/wps.20115

Grant, J. E., Levine, L., Kim, D., \& Potenza, M. N. (2005). Impulse control disorders in adult psychiatric inpatients. American Journal of Psychiatry, 162(11), 2184-2188. doi:10.1176/ appi.ajp.162.11.2184

Griffiths, M. D. (2016). Compulsive sexual behaviour as a behavioural addiction: The impact of the Internet and other issues. Addiction, 111(12), 2107-2108. doi:10.1111/add.13315

Jaisoorya, T. S., Reddy, Y. J., \& Srinath, S. (2003). The relationship of obsessive-compulsive disorder to putative spectrum disorders: Results from an Indian study. Comprehensive Psychiatry, 44(4), 317-323. doi:10.1016/S0010-440X(03)00084-1

Jenike, M. A. (1989). Obsessive-compulsive and related disorders: A hidden epidemic. The New England Journal of Medicine, 321(8), 539-541. doi:10.1056/NEJM198908243210811

Judd, L. L., \& Akiskal, H. S. (2003). The prevalence and disability of bipolar spectrum disorders in the US population: Re-analysis of the ECA database taking into account subthreshold cases. Journal of Affective Disorders, 73(1-2), 123-131. doi:10.1016/S0165-0327(02)00332-4

Kafka, M. P. (2010). Hypersexual disorder: A proposed diagnosis for DSM-V. Archives of Sexual Behavior, 39(2), 377-400. doi:10.1007/s10508-009-9574-7
Kafka, M. P. (2014). What happened to hypersexual disorder? Archives of Sexual Behavior, 43(7), 1259-1261. doi:10.1007/ s10508-014-0326-y

Klein, V., Briken, P., Schröder, J., \& Fuss, J. (in press). Mental health professionals' pathologization of compulsive sexual behavior: Do clients' gender and sexual orientation matter? Journal of Abnormal Psychology.

Klein, V., Rettenberger, M., \& Briken, P. (2014). Self-reported indicators of hypersexuality and its correlates in a female online sample. The Journal of Sexual Medicine, 11(8), 1974-1981. doi:10.1111/jsm.12602

Kraus, S. W., Krueger, R. B., Briken, P., First, M. B., Stein, D. J., Kaplan, M. S., Voon, V., Abdo, C. H. N., Grant, J. E., Atalla, E., \& Reed, G. M. (2018). Compulsive sexual behaviour disorder in the ICD-11. World Psychiatry, 17(1), 109-110. doi:10.1002/wps.20499

Kraus, S. W., Voon, V., \& Potenza, M. N. (2016). Should compulsive sexual behavior be considered an addiction? Addiction, 111(12), 2097-2106. doi:10.1111/add.13297

Langstrom, N., \& Hanson, R. K. (2006). High rates of sexual behavior in the general population: Correlates and predictors. Archives of Sexual Behavior, 35(1), 37-52. doi:10.1007/ s10508-006-8993-y

Morgenstern, J., Muench, F., O’Leary, A., Wainberg, M., Parsons, J. T., Hollander, E., Blain, L., \& Irwin, T. (2011). Non-paraphilic compulsive sexual behavior and psychiatric comorbidities in gay and bisexual men. Sexual Addiction \& Compulsivity, 18(3), 114-134. doi:10.1080/10720162.2011.593420

Odlaug, B. L., Lust, K., Schreiber, L. R., Christenson, G., Derbyshire, K., Harvanko, A., Golden, D., \& Grant, J. E. (2013). Compulsive sexual behavior in young adults. Annals of Clinical Psychiatry, 25(3), 193-200.

Pauls, D. L., Leckman, J. F., Towbin, K. E., Zahner, G. E., \& Cohen, D. J. (1986). A possible genetic relationship exists between Tourette's syndrome and obsessive-compulsive disorder. Psychopharmacology Bulletin, 22(3), 730-733.

Pauls, D. L., Towbin, K. E., Leckman, J. F., Zahner, G. E., \& Cohen, D. J. (1986). Gilles de la Tourette's syndrome and obsessive-compulsive disorder: Evidence supporting a genetic relationship. Archives of General Psychiatry, 43(12), 1180-1182. doi:10.1001/archpsyc.1986.01800120066013

Potenza, M. N., Gola, M., Voon, V., Kor, A., \& Kraus, S. W. (2017). Is excessive sexual behaviour an addictive disorder? Lancet Psychiatry, 4(9), 663-664. doi:10.1016/S22150366(17)30316-4

Raymond, N. C., Coleman, E., \& Miner, M. H. (2003). Psychiatric comorbidity and compulsive/impulsive traits in compulsive sexual behavior. Comprehensive Psychiatry, 44(5), 370-380. doi:10.1016/S0010-440X(03)00110-X

Salkovskis, P. M., \& Warwick, H. M. (1986). Morbid preoccupations, health anxiety and reassurance: A cognitive-behavioural approach to hypochondriasis. Behaviour Research and Therapy, 24(5), 597-602. doi:10.1016/0005-7967(86)90041-0

Skegg, K., Nada-Raja, S., Dickson, N., \& Paul, C. (2010). Perceived "out of control" sexual behavior in a cohort of young adults from the Dunedin Multidisciplinary Health and Development Study. Archives of Sexual Behavior, 39(4), 968-978. doi:10.1007/s10508-009-9504-8

Smith, P. H., Potenza, M. N., Mazure, C. M., McKee, S. A., Park, C. L., \& Hoff, R. A. (2014). Compulsive sexual behavior among male military veterans: Prevalence and associated 
clinical factors. Journal of Behavioral Addictions, 3(4), 214-222. doi:10.1556/JBA.3.2014.4.2

Stein, D. J. (2008). Classifying hypersexual disorders: Compulsive, impulsive, and addictive models. Psychiatric Clinics of North America, 31(4), 587-591. doi:10.1016/j.psc.2008.06.007

Stein, D. J., Black, D. W., \& Pienaar, W. (2000). Sexual disorders not otherwise specified: Compulsive, addictive, or impulsive? CNS Spectrums, 5(1), 60-66. doi:10.1017/S1092852900012670
Stein, D. J., Hugo, F., Oosthuizen, P., Hawkridge, S. M., \& van Heerden, B. (2000). Neuropsychiatry of hypersexuality. CNS Spectrums, 5(1), 36-46. doi:10.1017/S1092852900012657

Swain, J. E., Scahill, L., Lombroso, P. J., King, R. A., \& Leckman, J. F. (2007). Tourette syndrome and tic disorders: A decade of progress. Journal of the American Academy of Child \& Adolescent Psychiatry, 46(8), 947-968. doi:10.1097/chi. 0b013e318068fbcc 